\title{
Catalytic CVD processes of oxidizing species and the prevention of oxidization of heated tungsten filaments by $\mathrm{H}_{2}$
}

\author{
Hironobu Umemoto ${ }^{1, *}$, S.G. Ansari ${ }^{2,3}$, Takashi Morimoto ${ }^{2}$, Shota Setoguchi ${ }^{2}$, Hitoshi \\ Uemura $^{2}$, Hideki Matsumura ${ }^{2}$ \\ ${ }^{1}$ Faculty of Engineering, Shizuoka University, Johoku, Hamamatsu, Shizuoka 432-8561, \\ Japan \\ ${ }^{2}$ School of Materials Science, Japan Advanced Institute of Science and Technology, \\ Asahidai, Nomi, Ishikawa 923-1292, Japan \\ ${ }^{3}$ Present address: Thin Film Technology Lab, School of Chemical Engineering, Chonbuk \\ National University, Chonju, Chonbuk 561756, Korea
}

\begin{abstract}
The catalytic decomposition conditions of $\mathrm{O}_{2}, \mathrm{~N}_{2} \mathrm{O}$ and $\mathrm{NO}$ were investigated to avoid oxidization of heated tungsten filaments. It was confirmed that no oxidization takes place in the presence of an excess amount of $\mathrm{H}_{2}$ or $\mathrm{NH}_{3}$; for example, when the catalyzer temperature is $1990 \mathrm{~K}$ and the $\mathrm{H}_{2} / \mathrm{O}_{2}$ flow rate ratio is more than 18. These results are consistent with the recent results that no oxidization is observed in the $\mathrm{SiH}_{4} / \mathrm{NH}_{3} / \mathrm{H}_{2} / \mathrm{O}_{2} / \mathrm{He}$ system to deposit $\mathrm{SiO}_{\mathrm{x}} \mathrm{N}_{\mathrm{y}}$ films as long as the $\mathrm{O}_{2}$ flow rate is low. In addition, it was revealed that in this $\mathrm{SiH}_{4} / \mathrm{NH}_{3} / \mathrm{H}_{2} / \mathrm{O}_{2} / \mathrm{He}$ system, $\mathrm{O}_{2}$ is not only decomposed on the catalyzer surfaces but also is consumed in homogeneous and/or heterogeneous reactions. One of the consumption paths in the gas phase should be the reaction with $\mathrm{SiH}_{3}$ to produce $\mathrm{SiO}$
\end{abstract}




\section{Keywords}

Catalytic chemical vapor deposition, Cat-CVD, Hot-Wire CVD, Oxygen, Oxidization, $\mathrm{SiO}_{\mathrm{x}} \mathrm{N}_{\mathrm{y}}$

*Corresponding author. Tel.: +81-53-478-1275; fax: +81-53-478-1275.

E-mail address: thumemo(at)ipc.shizuoka.ac.jp (H. Umemoto).

\section{Introduction}

One of the weak points in catalytic chemical vapor deposition (Cat-CVD, often called Hot-Wire CVD) processes compared to plasma-enhanced CVD (PECVD) is that it is difficult to use oxidizing species as a material gas. This is because tungsten, one of the most widely used catalyzer materials, is easily oxidized and the vapor pressure of tungsten oxide is much higher than that of tungsten metal. According to Ogita and his coworkers, the typical lifetime of tungsten catalyzers used in the presence of trimethyl aluminum and $\mathrm{O}_{2}$ to deposit $\mathrm{Al}_{2} \mathrm{O}_{3}$ is as short as $25 \mathrm{~min}$ [1,2]. This problem can be avoided by using Ir instead of W [3,4]. However, Ir is much more expensive than W. In addition, in the presence of $\mathrm{SiH}_{4}$, Ir can make a low-melting-point alloy with $\mathrm{Si}$ [3].

In order to avoid the oxidization of $\mathrm{W}$ catalyzers, Izumi proposed the addition of $\mathrm{H}_{2}$ [5]. He tried to oxidize Si surfaces by the decomposition products of a $\mathrm{H}_{2} / \mathrm{O}_{2}$ mixture on heated $\mathrm{W}$ catalyzers. In order to avoid metal contamination, he carried out the oxidization with a $\mathrm{H}_{2} / \mathrm{O}_{2}$ flow rate ratio as large as 2000. However, it is not certain if this ratio is the critical one. More recently, Matsumoto et al. used a mixture of $\mathrm{SiH}_{4} / \mathrm{H}_{2} / \mathrm{O}_{2}$ to prepare $\mathrm{SiO}_{2}$ films [6,7]. The $\mathrm{H}_{2} / \mathrm{O}_{2}$ ratio was between 0.25 and 1.5 [8]. Although Matsumoto stated that the catalyzer lifetime was not changed by the introduction of $\mathrm{O}_{2}$, his reported lifetime, $8 \mathrm{~h}$, seems to be much shorter than that under typical deposition conditions of 
a-Si:H and poly-Si:H, which is more than $1000 \mathrm{~h}[7,9]$.

Recently, Ogawa et al. have reported that $\mathrm{SiO}_{\mathrm{x}} \mathrm{N}_{\mathrm{y}}$ films prepared from a mixture of $\mathrm{SiH}_{4} / \mathrm{NH}_{3} / \mathrm{H}_{2} / \mathrm{O}_{2}$ can be used as a buffer layer to reduce the stress in $\mathrm{SiN}_{\mathrm{x}}$ films and to prevent the formation of cracks in the passivation films [10]. The typical flow rates were $10 \mathrm{sccm}$ for $\mathrm{SiH}_{4}, 20$ sccm for $\mathrm{NH}_{3}, 400 \mathrm{sccm}$ for $\mathrm{H}_{2}$, and $300 \mathrm{sccm}$ for $2 \%$ He-diluted $\mathrm{O}_{2}$. The total pressure was kept at 20 Pa while the catalyzer temperature was $2020 \mathrm{~K}$. Under such conditions, no oxidization of W filaments was observed after several hours' use.

In the present work, the effect of $\mathrm{H}_{2} / \mathrm{O}_{2}$ and $\mathrm{NH}_{3} / \mathrm{O}_{2}$ flow rate conditions on preventing the oxidation of W filaments was investigated systematically. Both $\mathrm{H}_{2}$ and $\mathrm{NH}_{3}$ are known as reducing agents and by mixing these gases it should be possible to avoid oxidation. In addition, the consumption efficiencies of $\mathrm{O}_{2}$ were measured using a quadrupole mass spectrometric technique under various conditions including the deposition conditions for $\mathrm{SiO}_{\mathrm{x}} \mathrm{N}_{\mathrm{y}}$. The catalytic decomposition processes of $\mathrm{NO}$ and $\mathrm{N}_{2} \mathrm{O}$ were also examined.

\section{Experimental}

Two kinds of measurements were carried out. In the first, the DC voltage applied to the filament was fixed and the current was monitored as a function of time. When the filament is oxidized, there must be a variation in resistivity. A power supply made by Takasago Ltd. (EX-1125H2) was used to apply the voltage and to monitor the current. A tungsten wire, $0.5 \mathrm{~mm}$ in diameter and $20 \mathrm{~cm}$ in length, was used as a catalyzer. In the second measurement, a quadrupole mass-spectrometer (Anelva, M-QA200TS) was used to monitor the steady-state densities of the stable molecules, such as $\mathrm{O}_{2}$ and $\mathrm{SiH}_{4}$. The consumption efficiency of the material gas molecules can be obtained by comparing the signal intensities under catalyzer-heated and unheated conditions. The diameter and the length of the 
W wire were $0.4 \mathrm{~mm}$ and $120 \mathrm{~cm}$, respectively. The mass spectrometer was attached to the chamber through a sampling hole (0.4 mm in diameter), and was differentially pumped. The CVDchamber and other experimental apparatus were similar to those described elsewhere [11-13].

\section{Results and Discussion}

Figures 1 and 2 show the time dependence of the current when the applied voltage was fixed. The flow and voltage conditions (a)-(f) are summarized in table 1. The partial pressures of $\mathrm{O}_{2}$ were the same under all conditions. The voltages were adjusted to hold the initial filament temperatures constant. The initial temperatures estimated from the resistivities were 1990 and $2340 \mathrm{~K}$, respectively. The stepwise behavior is due to the limited resolution of the digital ammeter used.

At $1990 \mathrm{~K}$, the current is constant when the $\mathrm{H}_{2} / \mathrm{O}_{2}$ mixing ratio is larger than 18 , while at 2340 $\mathrm{K}$, it was impossible to keep the current constant even when the mixing ratio is as large as 100 . Intermediate results were obtained at intermediate temperatures. At $2160 \mathrm{~K}$, the current was constant when the ratio was over 60 . Similar results were obtained for $\mathrm{H}_{2} / \mathrm{NO}$ and $\mathrm{NH}_{3} / \mathrm{O}_{2}$ mixtures. In the $\mathrm{H}_{2} / \mathrm{NO}$ system, the oxidization could be ignored when the mixing ratio was over 38 at $1960 \mathrm{~K}$. As for the $\mathrm{NH}_{3} / \mathrm{O}_{2}$ system, the oxidization was minor when the catalyzer temperature was $2150 \mathrm{~K}$ and the mixing ratio was over 22. In these systems, oxidization is minor when the mixing ratio is large and when the catalyzer temperature is low. On the other hand, in the $\mathrm{H}_{2} / \mathrm{N}_{2} \mathrm{O}$ system, the oxidization was less efficient at higher temperatures. When the catalyzer temperature was $2000 \mathrm{~K}$, it was necessary to increase the mixing ratio up to 60 to avoid the oxidization, while oxidization could be ignored at $2340 \mathrm{~K}$

when the ratio was 18. The situation for $\mathrm{N}_{2} \mathrm{O}$ is similar to the silicidation of tungsten. Silicidation by neat $\mathrm{SiH}_{4}$ can be ignored when the catalyzer temperature is over $1900 \mathrm{~K}$. Here, it may seem that $\mathrm{N}_{2} \mathrm{O}$ is a better oxidization material because it is possible to increase the catalyzer temperature. However, 
quadrupole mass spectrometric measurements showed that the decomposition efficiency of $\mathrm{N}_{2} \mathrm{O}$ is much lower than those of $\mathrm{O}_{2}$ and NO. When the flow rate ratio of $\mathrm{H}_{2} /$ oxides is fixed at 60 and the total pressure at $26 \mathrm{~Pa}$, the decomposition efficiencies of $\mathrm{O}_{2}$ and $\mathrm{NO}$ were $30 \%$ at $2070 \mathrm{~K}$, while that for $\mathrm{N}_{2} \mathrm{O}$ was only $17 \%$ at $2370 \mathrm{~K}$. The catalyzer temperature dependences of the decomposition efficiencies are plotted in Fig.3.

The above results on the $\mathrm{H}_{2} / \mathrm{O}_{2}$ system is consistent with those of Ogawa et al. who have shown that oxidization is minor when the flow rates of $\mathrm{SiH}_{4} / \mathrm{NH}_{3} / \mathrm{H}_{2} / \mathrm{O}_{2} / \mathrm{He}$ are 10/20/400/6/294 sccm at a catalyzer temperature of $2020 \mathrm{~K}$ [10]. In order to evaluate the consumption efficiencies of the material gases under these conditions, we carried out mass-spectrometric measurements under the same conditions. The results are illustrated in Fig. 4. It should be noted here that the consumption efficiency of $\mathrm{O}_{2}$ in this system is more than that in $\mathrm{H}_{2} / \mathrm{O}_{2}$ system. The direct reaction of $\mathrm{O}_{2}$ with $\mathrm{SiH}_{4}$ is not the cause of the decrease. The $\mathrm{O}_{2}$ signal did not decrease unless the catalyzer was heated. Table 2 lists the consumption efficiencies of the material gases under various flow conditions. The total pressure and the catalyzer temperature were kept at $20 \mathrm{~Pa}$ and $2020 \mathrm{~K}$, respectively. According to table 2, the consumption efficiency of $\mathrm{O}_{2}$ increases rapidly by the introduction of $\mathrm{SiH}_{4}$. Similar results were obtained in the $\mathrm{SiH}_{4} / \mathrm{NH}_{3} / \mathrm{H}_{2} / \mathrm{NO} / \mathrm{He}$ and $\mathrm{SiH}_{4} / \mathrm{NH}_{3} / \mathrm{H}_{2} / \mathrm{N}_{2} \mathrm{O} / \mathrm{He}$ systems. In the presence of an excess amount of $\mathrm{H}_{2}$, $\mathrm{SiH}_{4}$ can easily be converted to $\mathrm{SiH}_{3}$ radicals by the reaction with $\mathrm{H}$ atoms produced from $\mathrm{H}_{2}[14,15]$. $\mathrm{SiH}_{3}$ may react with $\mathrm{O}_{2}$ rapidly to produce $\mathrm{SiO}[16,17]$ and $\mathrm{SiO}$ may be one of the major deposition species in this system. Another possible consumption path is the reaction on chamber walls and substrate surfaces activated by the deposition of $\mathrm{SiH}_{3}$. The recombination processes of $\mathrm{O}$ atoms on chamber walls may also be suppressed by the deposition of Si compounds. Finally, as is shown in table 2, the consumption efficiency of $\mathrm{NH}_{3}$ decreases with the introduction of both $\mathrm{SiH}_{4}$ and $\mathrm{O}_{2}$. The decrease caused by $\mathrm{SiH}_{4}$ has been explained as the poisoning of the catalyzer surfaces [12,13]. A similar mechanism may be assumed for $\mathrm{O}_{2}$. It should be noted, however, that there are no synergistic 
effects.

\section{Conclusions}

The catalytic decomposition processes of $\mathrm{O}_{2}, \mathrm{NO}$ and $\mathrm{N}_{2} \mathrm{O}$ were examined, paying special attention to the deposition of $\mathrm{SiO}_{\mathrm{x}} \mathrm{N}_{\mathrm{y}}$ films. The oxidization of the $\mathrm{W}$ catalyzer can be avoided by introducing an excess amount of $\mathrm{H}_{2}$ or $\mathrm{NH}_{3}$. These results will make it possible to increase the lifetime of $\mathrm{W}$ as a catalyzer material. The consumption efficiency was the highest for $\mathrm{O}_{2}$ among the oxidizing species, exceeding $90 \%$ in the presence of $\mathrm{SiH}_{4}$ and $\mathrm{H}_{2} \cdot \mathrm{O}_{2}$ is not only decomposed on heated catalyzer surfaces, but also is lost in reactions in the gas-phase or on surfaces activated by the deposition of Si-related compounds. 


\section{References}

[1] Y. Ogita, S. Iehara, T. Tomita, Thin Solid Films 430 (2003) 161.

[2] Y. Ogita, T. Tomita, Thin Solid Films 501 (2006) 39.

[3] K. Saito, Y. Uchiyama, K. Abe, Thin Solid Films 430 (2003) 287.

[4] Y. Ogita, T. Tomita, Thin Solid Films 501 (2006) 35.

[5] A. Izumi, Thin Solid Films 395 (2001) 260.

[6] Y. Matsumoto, M. Ortega, J.-M. Peza, M.-A. Reyes, A. Escobosa, Thin Solid Films 490 (2005) 173.

[7] Y. Matsumoto, Thin Solid Films 501 (2006) 95.

[8] Y. Matsumoto, private communication

[9] H. Matsumura, Jpn. J. Appl. Phys. Part 137 (1998) 3175.

[10] Y. Ogawa, K. Ohdaira, T. Oyaidu, H. Matsumura, Extended Abstracts (4th International Conference on Hot-Wire CVD (Cat-CVD) Process, 2006), p. 240.

[11] Y. Nozaki, K. Kongo, T. Miyazaki, M. Kitazoe, K. Horii, H. Umemoto, A. Masuda, H. Matsumura, J. Appl. Phys. 88 (2000) 5437.

[12] H. Umemoto, T. Morimoto, M. Yamawaki, Y. Masuda, A. Masuda, H. Matsumura, Thin Solid Films 430 (2003) 24.

[13] S.G. Ansari, H. Umemoto, T. Morimoto, K. Yoneyama, A. Izumi, A. Masuda, H. Matsumura, Thin Solid Films 501 (2006) 31.

[14] N.L. Arthur, L.A. Miles, Chem. Phys. Lett. 282 (1998) 192.

[15] Y. Nozaki, M. Kitazoe, K. Horii, H. Umemoto, A. Masuda, H. Matsumura, Thin Solid Films 395 (2001) 47.

[16] M. Koshi, N. Nishida, Y. Murakami, H. Matsui, J. Phys. Chem. 97 (1993) 4473.

[17]. Y. Murakami, M. Koshi, H. Matsui, K. Kamiya, H. Umeyama, J. Phys. Chem. 100 (1996) 17501. 


\section{List of table and figure captions}

Table 1 Flow and applied voltage conditions for the measurements in Figs.1 and 2

Table 2 Gas consumption efficiencies in the $\mathrm{SiH}_{4} / \mathrm{NH}_{3} / \mathrm{H}_{2} / \mathrm{O}_{2} / \mathrm{He}$ system. The total pressure and the catalyzer temperature were $20 \mathrm{~Pa}$ and $2020 \mathrm{~K}$, respectively.

Fig. 1 Filament current in the $\mathrm{H}_{2} / \mathrm{O}_{2}$ system as a function of time. The applied voltage was fixed. The initial filament temperature was $1990 \mathrm{~K}$.

Fig. 2 Filament current in the $\mathrm{H}_{2} / \mathrm{O}_{2}$ system as a function of time. The applied voltage was fixed. The initial filament temperature was $2340 \mathrm{~K}$.

Fig.3 Catalyzer temperature dependences of the decomposition efficiencies of $\mathrm{O}_{2}, \mathrm{NO}$ and $\mathrm{N}_{2} \mathrm{O}$.

Fig. 4 Mass spectrometric spectra in the $\mathrm{SiH}_{4} / \mathrm{NH}_{3} / \mathrm{H}_{2} / \mathrm{O}_{2} / \mathrm{He}$ system. 
Table 1

\begin{tabular}{|c|c|c|c|c|c|}
\hline & \multicolumn{2}{|c|}{ Flow rate / sccm } & \multirow{2}{*}{$\begin{array}{c}\text { Total pressure / } \\
\text { Pa }\end{array}$} & \multirow{2}{*}{$\begin{array}{c}\text { Applied voltage in } \\
\text { Fig.1 / V }\end{array}$} & \multirow{2}{*}{$\begin{array}{c}\text { Applied voltage in } \\
\text { Fig. } 2 \text { / V }\end{array}$} \\
\hline & $\mathrm{H}_{2}$ & $\mathrm{O}_{2}$ & & & \\
\hline (a) & 1000 & 10 & 45 & 5.1 & 7.5 \\
\hline (b) & 800 & 10 & 34 & 5.0 & 6.9 \\
\hline (c) & 600 & 10 & 26 & 4.9 & 6.6 \\
\hline (d) & 300 & 8.0 & 16 & 4.8 & 6.4 \\
\hline (e) & 100 & 5.5 & 8.0 & 4.8 & 5.9 \\
\hline (f) & 0 & 1.0 & 0.43 & 4.7 & 5.5 \\
\hline
\end{tabular}


Table 2

\begin{tabular}{cccccccc}
\hline & \multicolumn{3}{c}{ Flow rate / sccm } & & & \multicolumn{3}{c}{ Consumption efficiency / \% } \\
\cline { 1 - 1 } $\mathrm{SiH}_{4}$ & $\mathrm{NH}_{3}$ & $\mathrm{H}_{2}$ & $\mathrm{O}_{2}$ & & $\mathrm{SiH}_{4}$ & $\mathrm{NH}_{3}$ & $\mathrm{O}_{2}$ \\
\hline & & 400 & 6 & & & & 22 \\
& 20 & 400 & 6 & & & 10 & 23 \\
10 & & 400 & 6 & & 84 & & 94 \\
10 & 20 & 400 & 6 & & 94 & 28 & 99 \\
10 & 20 & 400 & & & 72 & 29 & \\
& 20 & 400 & & & 41 & \\
\hline
\end{tabular}




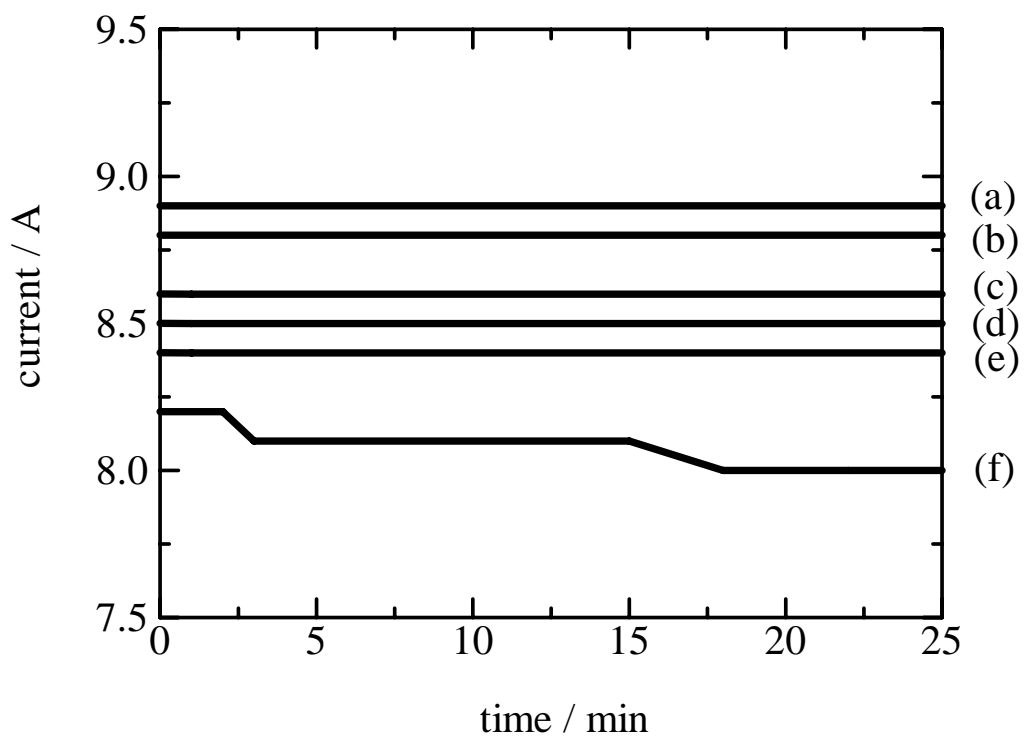

Fig. 1 H. Umemoto et al. 


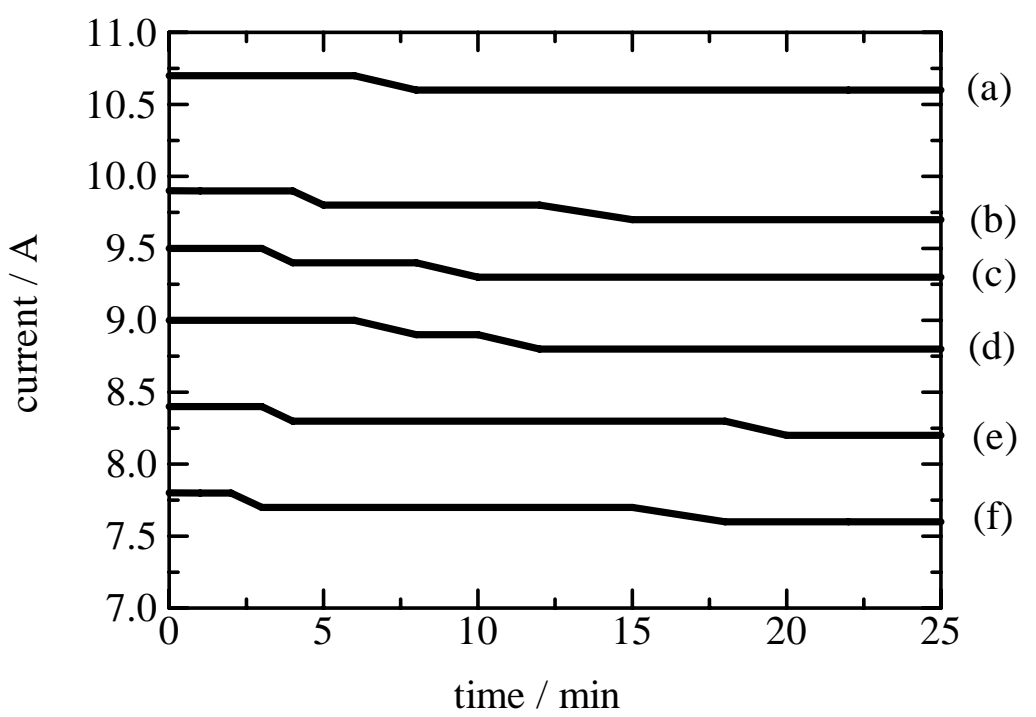

Fig.2 H. Umemoto et al. 


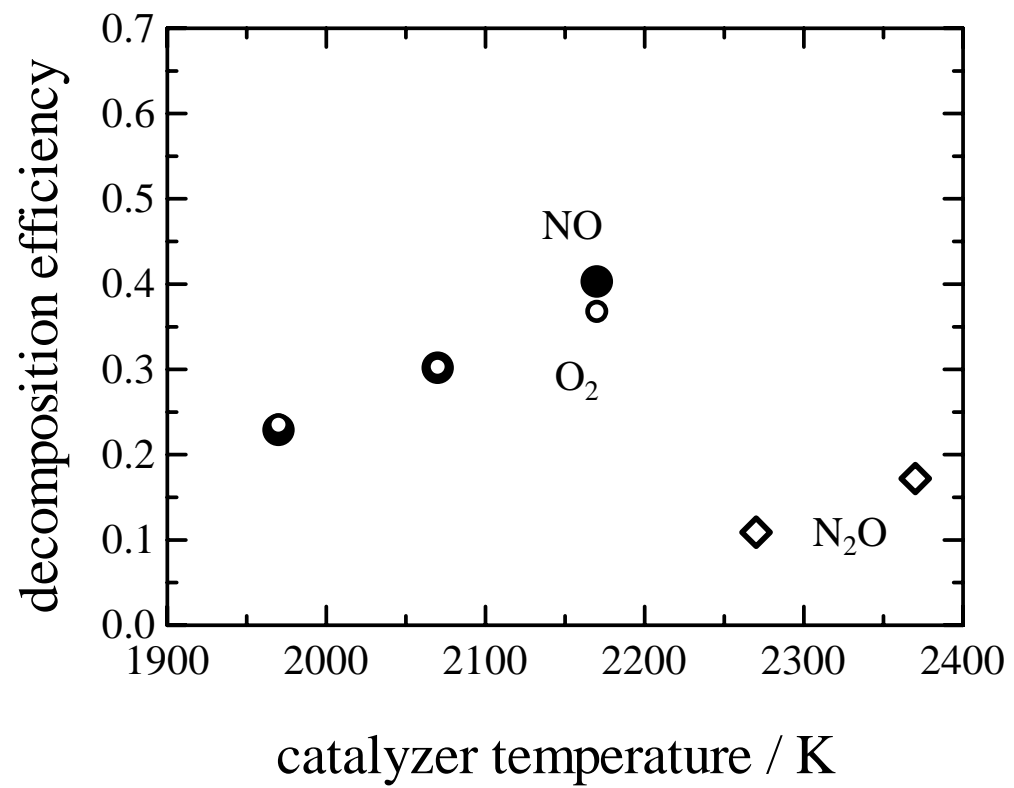

Fig.3 H. Umemoto et al. 


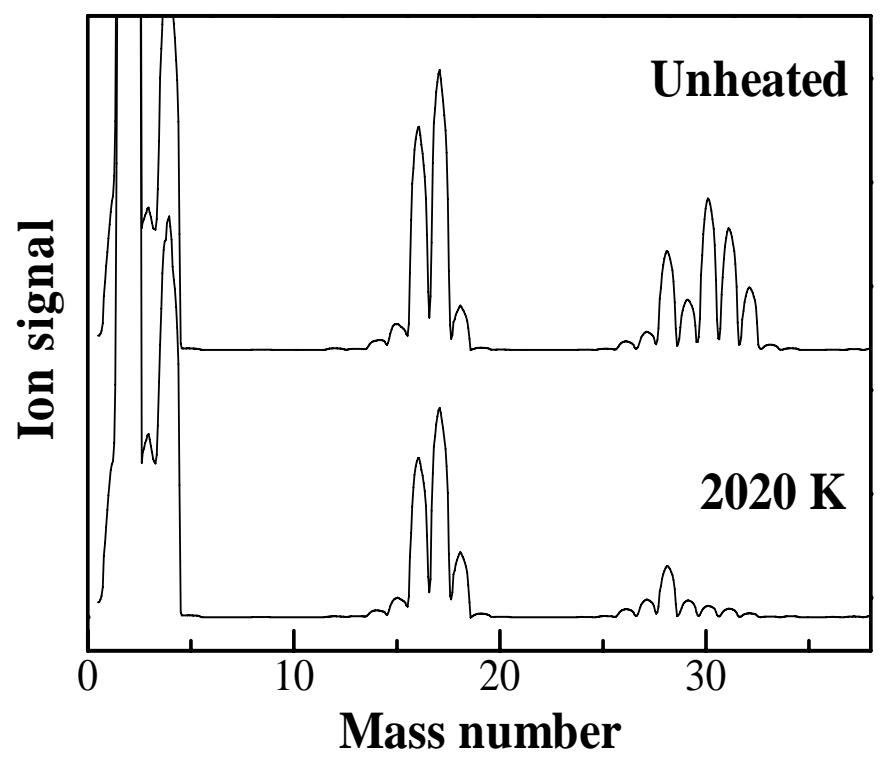

Fig.4 H. Umemoto et al. 